\title{
VIRTUAL MACHINES IN EDUCATION - CNC MILLING MACHINE WITH SINUMERIK 840D CONTROL SYSTEM
}

\author{
Ireneusz Zagórski ${ }^{1}$, Marcin Barszcz ${ }^{2}$ \\ 1 Department of Production Engineering, Mechanical Engineering Faculty, Lublin University of Technology, 36 \\ Nadbystrzycka Str., 20-618 Lublin, Poland, e-mail: i.zagorski@pollub.pl \\ 2 Department of Fundamentals of Technology, Technology Fundamentals Faculty, Lublin University of Techno- \\ logy, 38 Nadbystrzycka Str., 20-618 Lublin, Poland, e-mail: m.barszcz@pollub.pl
}

Received: 2014.09.30

Accepted: 2014.10.25

Published: 2014.12.01

\begin{abstract}
Machining process nowadays could not be conducted without its inseparable element: cutting edge and frequently numerically controlled milling machines. Milling and lathe machining centres comprise standard equipment in many companies of the machinery industry, e.g. automotive or aircraft. It is for that reason that tertiary education should account for this rising demand. This entails the introduction into the curricula the forms which enable visualisation of machining, milling process and virtual production as well as virtual machining centres simulation. Siemens Virtual Machine (Virtual Workshop) sets an example of such software, whose high functionality offers a range of learning experience, such as: learning the design of machine tools, their configuration, basic operation functions as well as basics of CNC.
\end{abstract}

Keywords: visualisation, virtual machine, milling machine, $\mathrm{CNC}$.

\section{INTRODUCTION, CURRENT STATE OF KNOWLEDGE}

Constant development of computer and information technology is reflected in ever-growing interest of users in computer graphics. The self notion of computer graphics, however, is considerably broad and general and its division can be based on: the input format, the number of dimensions or the function it fulfils. According to the input format, we can distinguish the following types of graphics: vector, bitmap and fractal [1].

From the viewpoint of application of computer visualisation, of e.g. virtual machines or structural elements, vector graphics appears to be the most interesting. 2D vector graphics [1] can find application in recording technical configuration, whereas $3 \mathrm{D}$ vector graphics enables, for instance, modelling technical objects and model creation (of, for example machines, film or computer game characters), which through appropriate rendering and animation can create virtual reality.
The machine industry requires the work on such materials as aluminium, magnesium, titanium or nickel alloys. Frequently semi-finished products for such elements (automotive or aircraft) are made in the form of casts (Figure 1b) or plate of raw material (Figure 1a). Figure 1 presents such parts.

Manufacturing parts through machining demands application of modern machining tools. This requires effective milling techniques which would ensure optimum machine tool operation time, together with adequate quality, surface roughness to machining time correlation [10]. In milling the amount of material removed from a machined surface often amounts to $90 \%$, for that reason certain machining methods appear of preference, for example: HSM (High Speed Machining), HPM (High Performance Machining), HPC (High Performance Cutting) or HSC (High Speed Cutting) $[4,5,7,9]$.

A modern engineer would not be able to fulfil his duties without computer aided designing 
a)

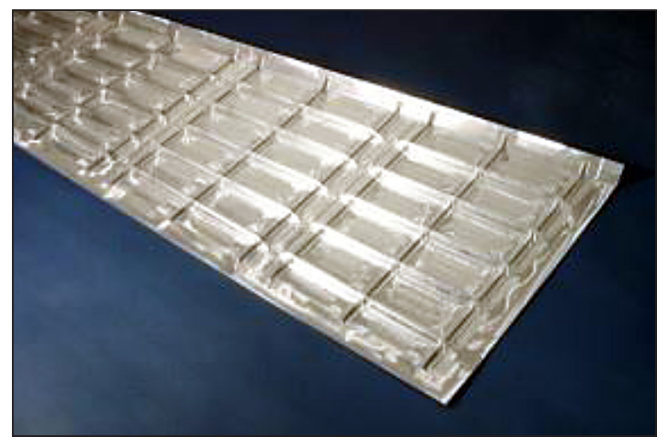

b)

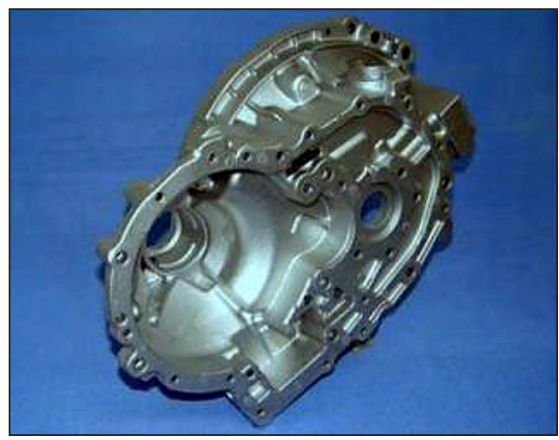

Fig. 1. Aircraft parts: a) aluminium alloy structural element, b) magnesium alloy transmission and clutch casing $[12,13]$

software CAD/CAM/CAE. A particularly notable place among tools of this sort is occupied by Solid Edge or NX by Siemens PLM Software, which are particularly useful and widely employed in both industrial and educational applications. Computer aided designing and manufacturing are examples of functionalities offered by advanced functions of CAD and NX system CAM modules which are of high educational value. Building virtual machine parks allows designing technological processes that would serve as an experiment and would not require using an actual machine. This opens the possibility to build virtual laboratories for educational purposes. Kinematic simulation of 3D milling machine models provides a highly realistic reflection of a process realised physically on the machine $[2$, $3]$. Figure 2 illustrates examples of modules and cabin, both designed in Modelling and NX Sheet Metal module of NX system.

Moreover, CAE computer software, using, inter alia, the finite element method (FEM), is capable of simulation (e.g. of external loads) and visualisation of conducted analyses, most frequently in a form of colour bitmaps, illustrating mesh nodes displacement or reduced stresses [6, 8]. Figure 3 presents model numerical simulations.

The presented examples derived from literature will provide the base for a more extensive analysis of potential of virtual machines and virtual machine parks at an introductory stage to courses discussing basics of numerically controlled machines.

\section{VIRTUAL WORKSHOP - MILLING CENTRE WITH SINUMERIK 840D CONTROL SYSTEM}

Modern aircraft elements are characterised by homogeneous structure, frequently made of monoblocks, manufactured on cutting edge numerically controlled machining centres [4]; hence the idea of introducing into the curriculum software enabling visualisation of a machining process in the form of virtual production and $\mathrm{CNC}$ machines. Figure 4 shows the main menu of Virtual Workshop. The software is available in two language versions - German and English. This is moreover the stage to select from two machining methods: turning or milling.

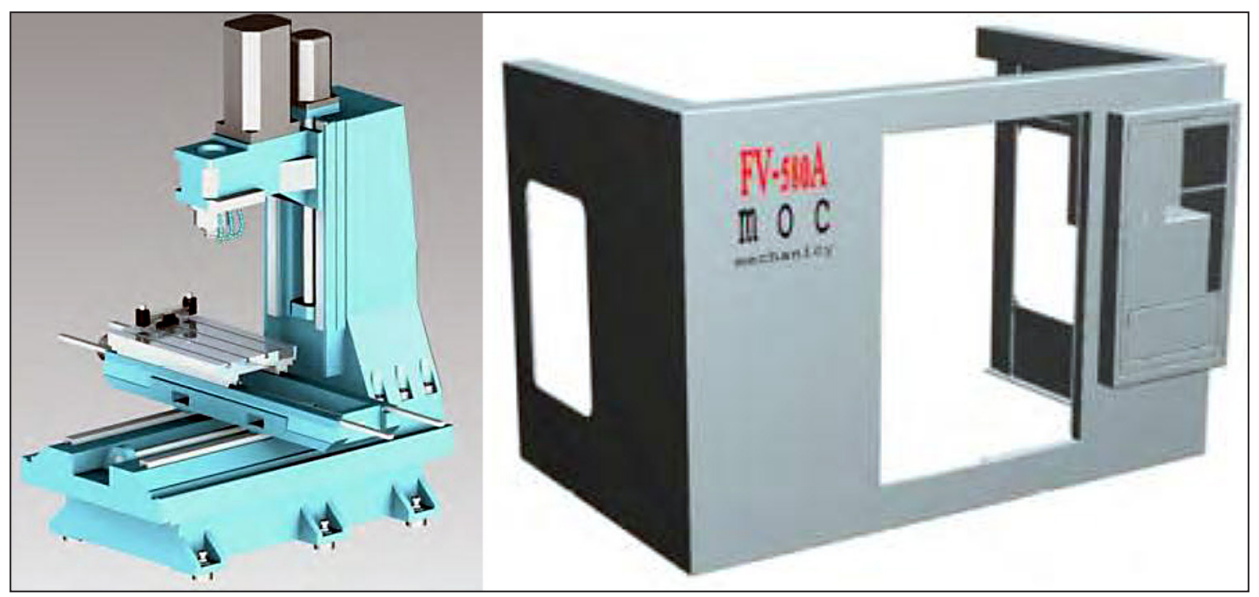

Fig. 2. Virtual machine building capabilities of NX system [2] 
a)

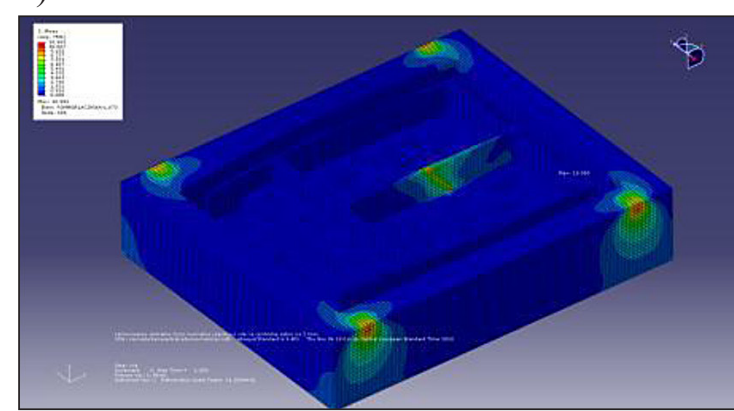

b)

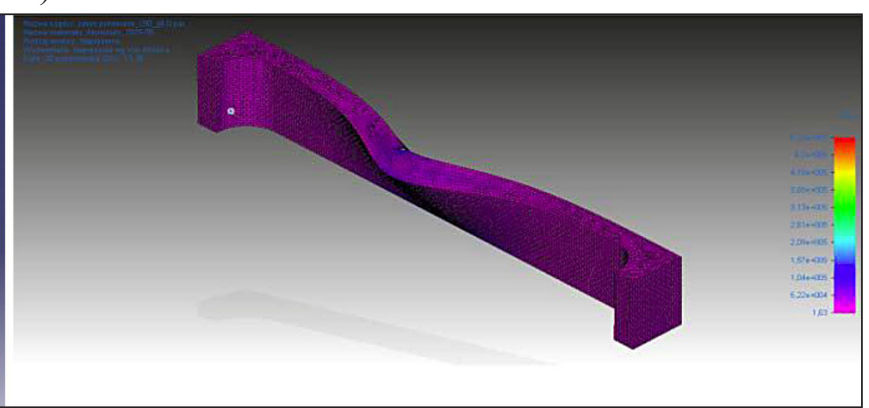

Fig. 3. FEM simulation on different software: a) Abaqus 6.9 EF1, b) Solid Edge ST4 (NX Nastran) [6, 8]

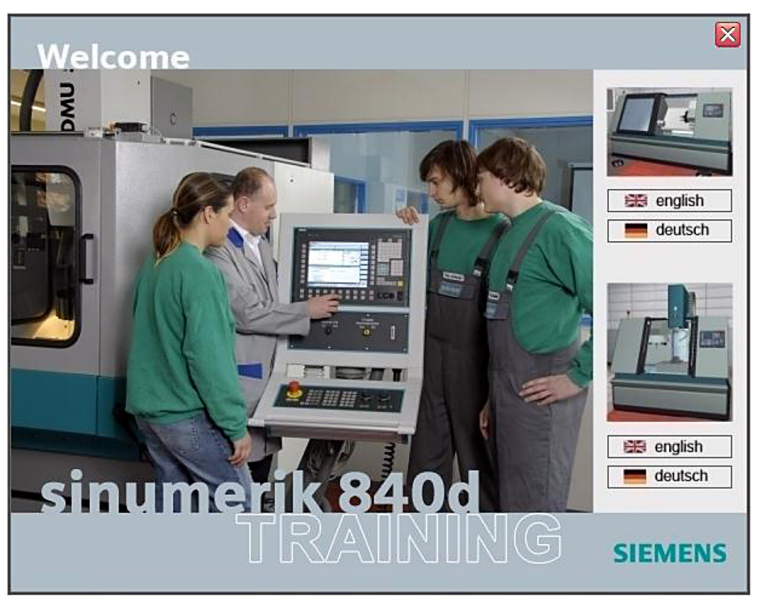

Fig. 4. Main menu [11]

The presented multimedia training software, Virtual Workshop, is available in the form of individual licenses for $\mathrm{PC}$, and it is a tool for selfstudy in CBT (Computer Based Training), enabling independent training on the basics of numerically controlled machines design as well as CNC technology [11]. Figure 5 presents a milling machine equipped with SINUMERIK 840D control system and an operator panel, which is loaded with the start of the machine.
The selection of milling machine opens three stages of training to choose from, namely:

- Machine familiarisation (Familiarisation with milling machine),

- Machine set-up (Sinumerik 840D - Milling),

- CNC basics (Milling fundamentals).

Each task group contains expandable tabs, offering information on the progress in each particular task.

\section{MACHINE FAMILIARISATION - FAMILIA- RISATION WITH MILLING MACHINE}

The first stage of training available in Machine familiarisation concerns the design of numerically controlled machines. This tab expands into 10 sub-groups regarding, as follows:

- Complete machine,

- Control Panel (links the user to a help mode, where all buttons in the Control Panel are described),

- Machine Bed (Ball screw drive Y axis, Guide $\mathrm{Y}$ axis, Servo motor $\mathrm{Y}$ axis),

- Machine column (Ball screw drive $Z$ axis, Guide $Z$ axis, Measuring system $Z$ axis),

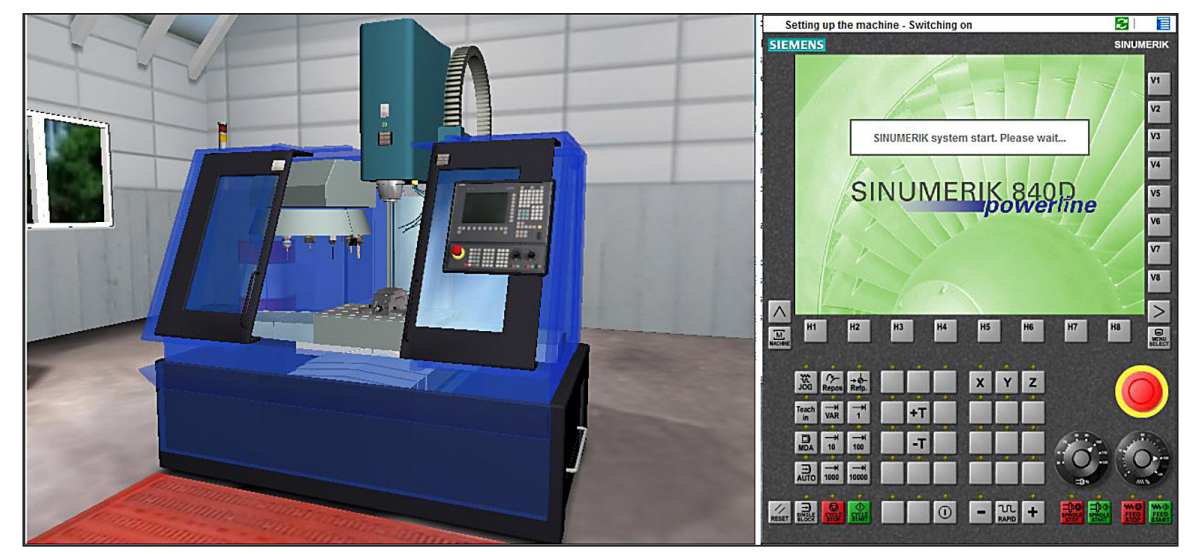

Fig. 5. CNC machining centre and operator panel [11] 
- Cross slide (Ball screw drive X axis, Guide X axis, Measuring system $\mathrm{X}$ axis),

- Spindle head (Main drive motor, Clamping cylinder, Centre sleeve),

- Clamping table (Vice, Clamping claws, Workpiece, Workpiece zero point, Machine zero point),

- Tool magazine (T1 Face-milling cutter $\mathrm{d}=$ $63 \mathrm{~mm}$, T2 Slot milling tool $\mathrm{d}=20 \mathrm{~mm}, \mathrm{~T} 3$ Slot milling tool $\mathrm{d}=10 \mathrm{~mm}$, T4 Spiral drilling tool $\mathrm{d}=8.5 \mathrm{~mm}$, T5 Thread drilling tool M10, T6 Remote measuring probe),

- Switch cabinet (Supply module, Control with drive module, PLC),

- Components (Cabin, Main switch, RH maintenance flap, LH maintenance flap, Coolant lubricant basin, Sliding lubricant basin, RH chip basin, LH chip basin, Status light).

At any given stage of work we can see 3D visualisation of individual elements of the machine. A panoramic view is available from a desired perspective by turning around the machine and zooming, all performed with keyboard. Figures 6 and 7 present examples of views at the first stage of Machine familiarisation.
The next two stages of training revolve around the notion of virtual machine operation and operator panel procedures in Machine set-up menu, while CNC essentials can be found in CNC basics. Individual menus contain task sub-groups with expandable working tasks, as in the case with Machine familiarisation.

\section{MACHINE SET-UP (SINUMERIK 840D - - MILLING)}

As it has been mentioned, the second stage of training in Machine set-up consists of two main task sub-groups, which are as follows:

- Setting up the machine (Switching on, Manual movement, Tool compensations, Workpiece zero point),

- Programming (Write a program, Edit a program, Operate a program).

The training at this stage consists in the following subsequent tasks appearing in the Information box, 'i', e.g.: 'Turn on the machine using the main switch and wait until the control system has started,' as shown in Figure 8.

a)

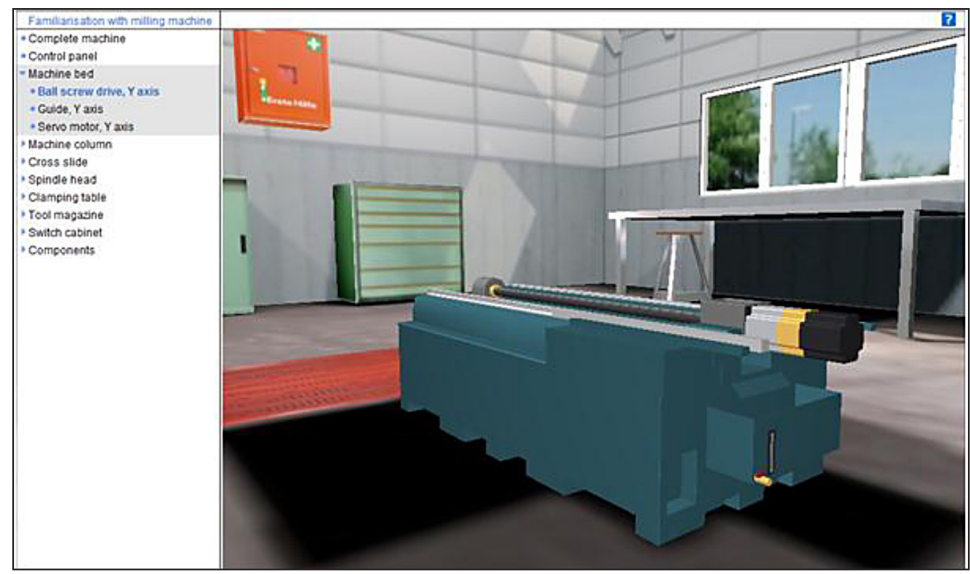

b)

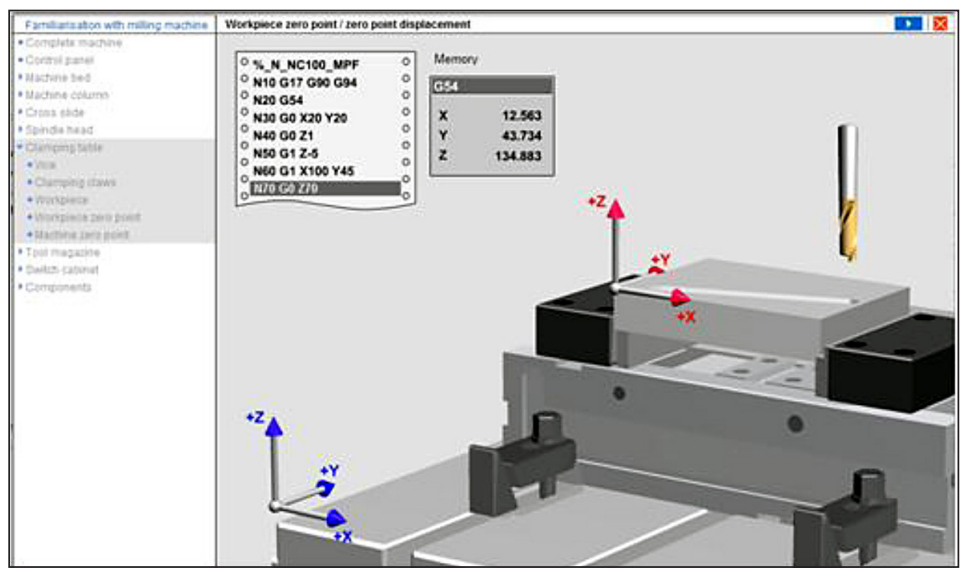

Fig. 6. Machine familiarization: a) Machine Bed and b) Clamping table (Workpiece zero point) [11] 


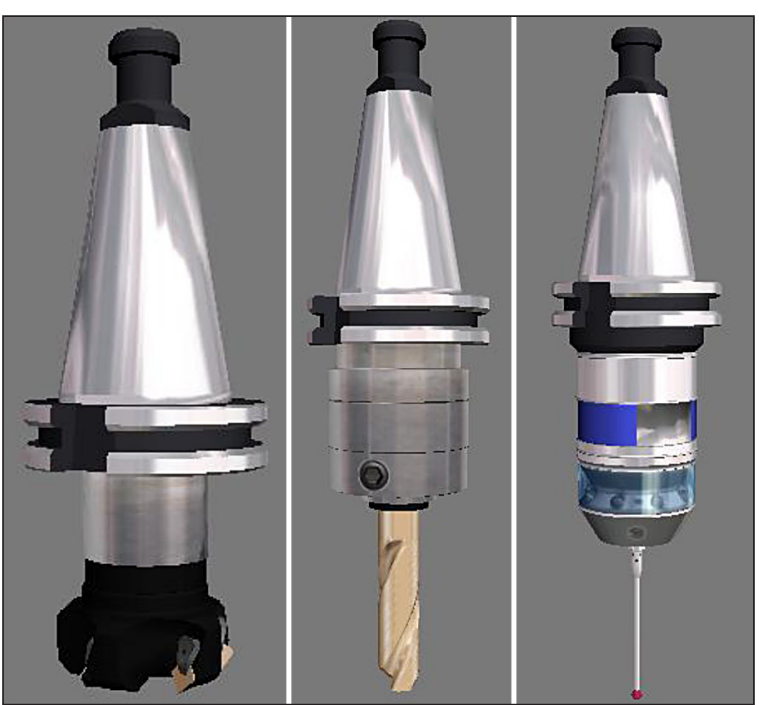

Fig. 7. Machine familiarization - Tool magazine: T1, T2, T6 [11]

We are given updates on completion of subsequent tasks within given task sub-groups, which are marked by ticking completed tasks.

\section{CNC BASICS (MILLING FUNDAMENTALS)}

The third, and final, stage of training, CNC basics, consists of four main task sub-groups, which, together with work tasks, describe the following:

- Training objective,

- Geometry (Coordinate systems, Points on workpiece, Absolute dimensions, Incremen- tal dimensions, Polar dimensions, Contour setting),

- Technology (Speed, Cutting speed, Feed rate, Feed/tooth),

- Programming (Program configuration, Program header, Addresses, Travel commands, Tool path compensation, Tool offsets, Cycles/ subroutines),

- Test it.

\section{CONCLUSIONS}

Dynamic development of computer graphics allows the creation of virtual models of machine parts, virtual technological machines, and consequently machine parks and virtual reality. Visualisation of machine parts geometry and virtual production (milling simulation) and virtual machines promotes our cognitive abilities. Therefore, it appears that this is the first step towards future stages of education and development of professional skills. The presented capabilities of Siemens software enable preliminary basic introduction of course participants into operation, programming and rudimentary knowledge regarding $\mathrm{CNC}$ machines.

Our future work will supplement the presented subject with available control functions in milling as well as the description of technological capabilities of the milling machine with the control system in question.

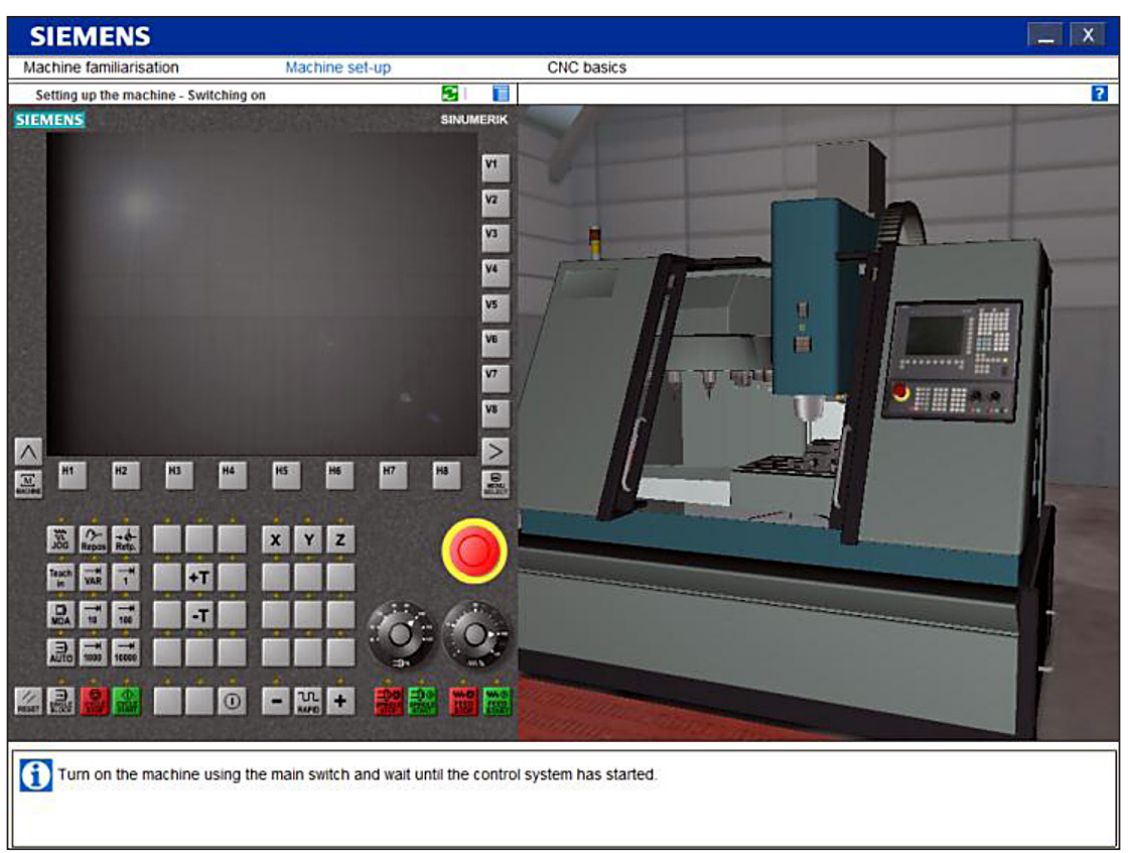

Fig. 8. Computer programme during Machine set-up training stage [11] 


\section{REFERENCES}

1. Dziedzic K., Lis R., Montusiewicz J.: Bitmap graphics in teaching multimedia techniques. Postępy Nauki i Techniki, 2, 2008, 140-152.

2. Józwik J., Włodarczyk M., Ścierka T.: Geometric and kinematics model of vertical CNC machine centre FV-580A. Postępy Nauki i Techniki, 5, 2010, 85-96.

3. Józwik J., Włodarczyk M., Ścierka T.: Virtual controller VNC of vertical CNC machine center FV580A. Postępy Nauki i Techniki, 5, 2010, 97-113.

4. Kuczmaszewski J.: Manufacturing effectiveness of aviation elements with aluminum and magnesium alloys. Komputerowo Zintegrowane Zarządzanie, Oficyna Wyd. Polskiego Towarzystwa Zarządzania Produkcją, Opole 2011, 7-18.

5. Oczoś K.E., Kawalec A.: Light metals forming. PWN, Warsaw 2012.

6. Pieśko P.: FEM analysis and experimental verification open and semi-open thin walls deformation. Report of the project No. POIG.01.01.02-00015/08-00

7. Pieśko P., Zagórski I.: Comparative analysis of
HSM, HPC and conventional milling methods of high-silicon aluminium. Postępy Nauki i Techniki, 7, 2011, 219-226.

8. Włodarczyk M.: Analysis of the influence of fixing and cutting forces on stress level in terms of the thickness of pocketing construction. Postępy Nauki i Techniki, 8, 2011, 82-92

9. Zagórski I., Kuczmaszewski J.: The study of cutting forces and their amplitudes during high-speed dry milling magnesium alloys. Advances in Science and Technology Research Journal, 7(20), 2013, 61-66.

10. Zagórski I., Pieśko P.: Comparative study of surface roughness of selected magnesium alloys after milling with carbide tool and PKD. Postępy Nauki i Techniki, 8, 2011, 53-58.

11. http://www.automatyka.siemens.pl, 2.06.2014.

12. http://agmetalminer.com/2010/03/29/new-airframe-construction-techniques-lowers-both-manufacturing-and-in-service-costs/, 4.07.2014.

13. Strazzi E., Ferrari Ch.: Low energy consumption and environmental friend process formagnesium anodizing, http://www.italfinish.com/public/images/lowenergy1.pdf, 9.04.2010. 